\title{
GeneXpert in the diagnosis of smear-negative PTB
}

\author{
Beuy Joob ${ }^{1}$, Viroj Wiwanitkit ${ }^{2}$
}

1. Sanitation 1 Medical Academic Center, Bangkok Thailand

2.Hainan Medical University, China; Faculty of Medicine, University of Nis, Serbia; Joseph Ayobabalola University, Nigeria

African Health Sciences 2014; 14(2):494

DOI: http://dx.doi.org/10.4314/ahs.v14i2.33

Sir, the recent report on "GeneXpert in the diagnosis of smear-negative PTB" is very interesting [1]. As Nakiyingi et al. noted, the concern on cost effectiveness on this new TB diagnostic tool is needed [1]. In fact, the cost effectiveness of the test is still controversial issue [2]. The value seems dependent to the setting [2 3]. Also, Nakiyingi et al. raised an important point that GeneXpert can help fasten diagnosis. However, it is questionable whether we actually need such a very fast

\section{Corresponding author:}

Beuy Joob

Sanitation 1 Medical Academic

Center,

Bangkok Thailand

Email: beuyjoob@hotmail.com result. The GeneXpert might not add any important clinical usefulness to the use of classical culture.

\section{References}

1. Nakiyingi L, Nankabirwa H, Lamorde M. Tuberculosis diagnosis in resource-limited settings: Clinical use of GeneXpert in the diagnosis of smear-negative PTB: a case report. Afr Health Sci. 2013 Jun;13(2):522-4.

2. Muñoz L, Moure R, Porta N, Gonzalez L, Guerra R, Alcaide F, Santin M. GeneXpert ${ }^{\circledR}$ for smear-negative pulmonary tuberculosis: does it play a role in lowburden countries? Diagn Microbiol Infect Dis. 2013 Mar;75(3):325-6

3. Dowdy DW, Cattamanchi A, Steingart KR, Pai M. Is scale-up worth it? Challenges in economic analysis of diagnostic tests for tuberculosis. PLoS Med. 2011 Jul;8(7):e1001063. 